\title{
Comparative in vitro study of calcium phosphate ceramics for their potency as scaffolds for tissue engineering
}

\author{
Joanna Wójtowicz $^{\text {a }}$, Joanna Leszczyńska ${ }^{\mathrm{a}}$, Anna Chróścicka ${ }^{\mathrm{a}}$, Anna Ślósarczyk ${ }^{\mathrm{b}}$, \\ Zofia Paszkiewicz ${ }^{\mathrm{b}}$, Aneta Zima ${ }^{\mathrm{b}}$, Krzysztof Rożniatowski ${ }^{\mathrm{c}}$, Piotr Jeleń ${ }^{\mathrm{d}}$ and \\ Małgorzata Lewandowska-Szumieł ${ }^{\text {a,* }}$ \\ ${ }^{a}$ Department of Histology and Embryology, Medical University of Warsaw, Warsaw, Poland \\ ${ }^{\mathrm{b}}$ AGH - Faculty of Materials Science and Ceramics, University of Science and Technology, Cracow, \\ Poland \\ ${ }^{\mathrm{c}}$ Division of Materials Design, Faculty of Materials Science and Engineering, \\ Warsaw University of Technology, Warsaw, Poland \\ ${ }^{\mathrm{d}}$ Department of Biophysics and Human Physiology, Medical University of Warsaw, Warsaw, Poland
}

Received 2 July 2013

Accepted 13 November 2013

\begin{abstract}
.
BACKGROUND: Calcium phosphate ceramics have been widely considered as scaffolds for bone tissue engineering. Selection of the best support for cultured cells, crucial for tissue engineered systems, is still required.

OBJECTIVE: We examined three types of calcium phosphate compounds: $\alpha$-tricalcium phosphate - the most soluble one, carbonate hydroxyapatite - chemically the most similar to the bone mineral and biphasic calcium phosphate - with the best $i n$ vivo biocompatibility in order to select the best support for osteoblastic cells for tissue engineered systems.

METHODS: Human osteoblasts were tested in direct contact with both dense samples and 3D scaffolds in either static or dynamic culture. Cell viability, cell spreading, osteogenic cell capacity, and extracellular matrix production were examined.

RESULTS: The obtained data indicate that biphasic calcium phosphate is the optimal cell-supporting material. In addition, dynamic culture improved cell distribution in the scaffolds, enhanced production of the extracellular matrix and promoted cells osteogenic capacity.

CONCLUSIONS: Biphasic calcium phosphate should be recommended as the most suitable matrix for osteogenic cells expansion and differentiation in tissue engineered systems.
\end{abstract}

Keywords: Tissue engineering, ceramics, biphasic calcium phosphate, osteoblast, dynamic culture

\section{Introduction}

Calcium phosphates $(\mathrm{Ca}-\mathrm{P})$ have been for years intensively investigated as potential bone substitutes due to their similarity to a natural bone mineral [1-3]. Promising experimental findings resulted in a

\footnotetext{
*Address for correspondence: Małgorzata Lewandowska-Szumiel, Department of Histology and Embryology, Medical University of Warsaw, Chalubinskiego 5, 02-004 Warsaw, Poland. Tel.: +4822 6220029; Fax: +4822 6295282; E-mail: mszumiel@wum.edu.pl.
} 
broad offer of Ca-P products on the medical market [4]. Currently, of interest are not only ceramic powders, which are intended to be used as bone fillers or a crucial part of osteoinductive bone cements [5-7]. During the last decade a lot of attention has been paid to a potential use of $\mathrm{Ca}-\mathrm{P}$ as scaffolds for bone tissue engineered products (BTEPs), which are highly expected new generation of bone substitutes [8-11]. Classified as medicinal products and not medical devices, bone tissue engineered products are more demanding regarding their manufacturing, storage, delivery and a formal approval. Convincing results of animal experiments confirm a benefit from the presence of living cells in ceramic implants and therefore justify the application of $\mathrm{Ca}-\mathrm{P}$ as scaffolds for BTEPs. There is a wide set of $\mathrm{Ca}-\mathrm{P}$ ceramics which are considered for this purpose since they are in general well tolerated by cells in vitro and host tissues in vivo [12,13]. However, the successful implementation of BTEPs depends on optimization of all elements of the tissue engineered system. In BTEP, scaffold plays not only a role of a filler but must serve as a perfect support for cells in culture prior to implantation. Although a lot of data concerning cytocompatibility of various bioceramics are available, it is difficult to compare different materials if they originate from various sources. This is because cell response to the support depends not only on its chemical nature but also on many other factors related to the details of the manufacturing process. In the present study three types of Ca-P scaffolds obtained by similar technology in the same laboratory are compared as candidate scaffolds for BTEPs with particular emphasis put on the osteogenic cell response in vitro. They have been selected for various advantages coming from their chemical structure. Thus, alpha tricalcium phosphate $(\alpha \mathrm{TCP})$ - for its solubility [14,15], carbonate hydroxyapatite (CHA) for the chemical similarity to the bone [16,17], and biphasic calcium phosphate (BCP) - for the best in vivo biocompatibility [13,18-22]. The in vitro cell response toward BCP, CHA and $\alpha \mathrm{TCP}$ has been evaluated in order to select the most advantageous calcium phosphate composition for 3D expansion and differentiation of human osteoblasts. The comparison of the effects obtained by using static or dynamic culture conditions (for tissue engineered systems) based on these materials is also provided.

\section{Materials and methods}

\subsection{Calcium phosphates dense disks and porous scaffolds preparation}

\subsubsection{Preparation of the initial calcium phosphate (CaPs) powders}

Calcium phosphate powders i.e., HA, $\beta$ TCP, CHA and $\alpha \mathrm{TCP}$ were produced by a wet chemical method. In such synthesis $\mathrm{H}_{3} \mathrm{PO}_{4}$, $\left(\mathrm{NH}_{4}\right)_{2} \mathrm{HPO}_{4}$ (POCH, CENTRO-CHEM, Poland) and $\mathrm{CaO}$ (analytically pure - UBICHEM or LOBA Co.) were applied as the phosphorus and calcium reagents, respectively. Ammonium hydrogen carbonate $\left(\mathrm{NH}_{4} \mathrm{HCO}_{3}\right)$ was used as reactant introducing $\mathrm{CO}_{3}{ }^{2-}$ groups. $\mathrm{pH}$ of the reaction mixtures was stabilized with ammonium hydroxide solution. The suspensions were aged for $48 \mathrm{~h}$ at room temperature and decanted. The resultant precipitates after washing with deionized water and filtration were dried at $90^{\circ} \mathrm{C}$ and ground to the size below $0.06 \mathrm{~mm}$. HA and $\beta$ TCP powders were calcined at $800^{\circ} \mathrm{C}$ in air atmosphere, whereas $\alpha \mathrm{TCP}$ powder at $950^{\circ} \mathrm{C}$. BCP powder was obtained by mixing $\mathrm{HA}$ and $\beta \mathrm{TCP}$ powders in the ratio 3:2.

\subsubsection{Preparation of dense ceramic disks}

The initial powders were pressed under the pressure of $100 \mathrm{MPa}$ to disks of $7.8 \mathrm{~mm}$ in diameter and $5 \mathrm{~mm}$ in height. The samples of BCP were sintered in air at $1250^{\circ} \mathrm{C}$ for $2 \mathrm{~h}, \alpha \mathrm{TCP}-$ at $1300^{\circ} \mathrm{C}$ for $5 \mathrm{~h}$, while the samples of $\mathrm{CHA}$ in $\mathrm{CO}_{2}$ atmosphere at $900^{\circ} \mathrm{C}$ for $1 \mathrm{~h}$. 


\subsubsection{Preparation of highly porous scaffolds}

CaPs powders were used to prepare the slurries designed for soaking polyurethane foams (EUROFOAM, Poland). Slurries containing 71-75 wt $\%$ of BCP, $\alpha$ TCP and $58 \mathrm{wt} \%$ of CHA were prepared. The powders were slowly added to distilled water under constant stirring. In order to stabilize and improve rheological properties of the suspensions the following dispersing agents were used: Dolapix PC-67 (Zchimmer and Schwarz, GmbH, Germany) in the form of 10\% solution and $0.5 \%$ solution of methylcellulose (Fluck). The scaffolds were fabricated via impregnating and drying polyurethane matrices. The sintering process was carried out as for dense samples. The obtained disks were of $12 \mathrm{~mm}$ in diameter and $4 \mathrm{~mm}$ in height.

\subsection{Characteristics of the materials}

Phase composition of the materials was determined by X-ray diffraction in the $2 \theta$ angle range of 10 $90^{\circ}$ using Philips X'Pert Pro Panalytical diffractometer. Quantitative phase analysis was made by the Rietveld method. Apparent density and total porosity dense ceramic disks was measured by Archimedes method. Apparent density of porous ceramic scaffolds was calculated from the mass and dimensions of minimum five samples having regular shapes. Total porosity of porous samples was evaluated based on the values of apparent and helium densities. The results are presented in Table 1.

Surface morphology of the materials was studied by SEM. The micrographs are shown in Fig. 1.

Table 1

Materials characteristics

\begin{tabular}{lllcccc}
\hline Material & \multicolumn{1}{c}{$\begin{array}{c}\text { Phase } \\
\text { composition } \\
(\mathrm{wt} \%)\end{array}$} & \multicolumn{1}{c}{ Type of material } & $\begin{array}{c}\text { Apparent } \\
\text { density } \\
\left(\mathrm{g} / \mathrm{cm}^{3}\right)\end{array}$ & $\begin{array}{c}\text { Total } \\
\text { porosity } \\
(\%)\end{array}$ & $\begin{array}{c}\text { Open } \\
\text { porosity } \\
\text { Po }(\%)\end{array}$ & $\begin{array}{c}\text { Water } \\
\text { absorbability } \\
\mathrm{N}(\%)\end{array}$ \\
\hline BCP & HA 59 & Dense ceramic disks $(\varnothing 6 \mathrm{~mm})$ & 3.029 & 2.3 & 0.3 & 0.1 \\
& $\beta \mathrm{TCP} 41.0$ & Porous ceramic scaffolds & $0.662-0.529$ & $78.6-82.9$ & - & - \\
CHA & HA 99.3 & Dense ceramic disks $(\varnothing 6 \mathrm{~mm})$ & 3.090 & 1.9 & 1.3 & 0.4 \\
& $\mathrm{CaO} 0.7$ & Porous ceramic scaffolds & $1.061-0.718$ & $66.3-77.1$ & - & - \\
\multirow{2}{*}{$\alpha \mathrm{TCP}$} & $\alpha \mathrm{TCP} 82.6$ & Dense ceramic disks $(\varnothing 6 \mathrm{~mm})$ & 2.828 & 1.1 & 0.8 & 0.3 \\
& HA 17.4 & Porous ceramic scaffolds & $0.606-0.535$ & $79.1-81.5$ & - & - \\
\hline
\end{tabular}

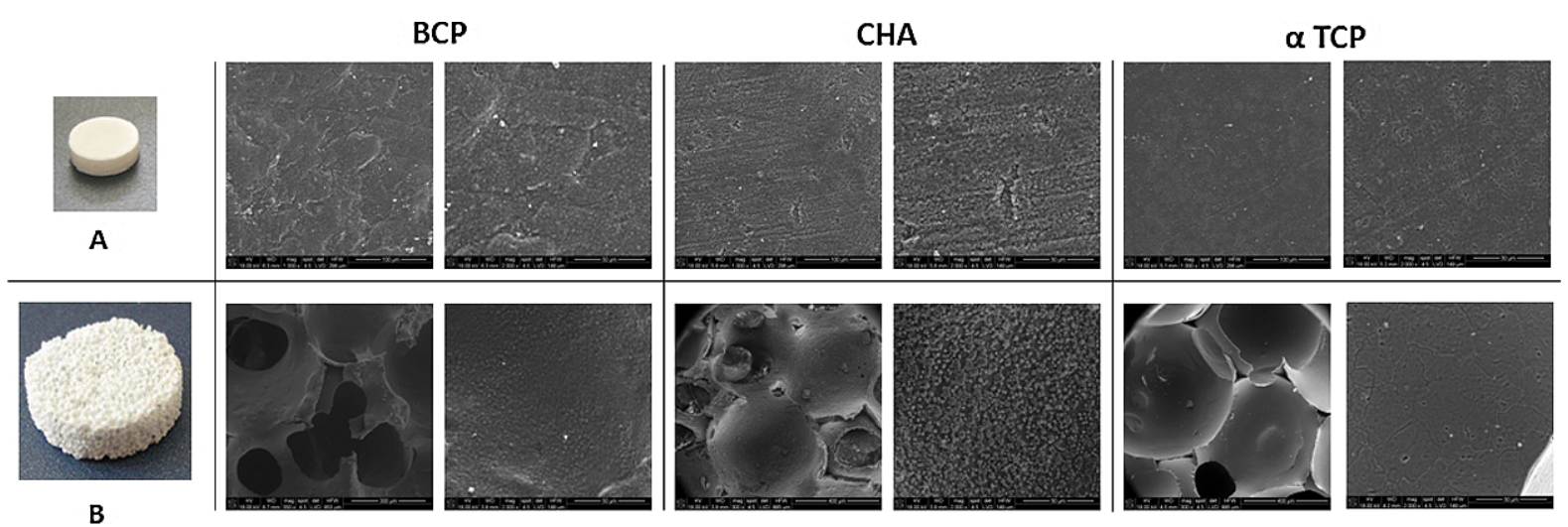

Fig. 1. Morphology of BCP, CHA and $\alpha \mathrm{TCP}$ - a macroscopic view and SEM pictures of all the investigated materials. (A) 2D dense disks; (B) 3D scaffolds. (Colors are visible in the online version of the article; http://dx.doi.org/10.3233/BME-140965.) 
The ceramic samples of $\mathrm{BCP}$, CHA and $\alpha \mathrm{TCP}$ were sterilized by radiation ( $25 \mathrm{kGy}$ ) prior to cell culture experiments.

\subsection{Isolation and culture of human bone derived cells}

Human bone derived cells (HBDCs) were used in all the described experiments. The cells were isolated according to Gallagher et al. [23]. Briefly, bone chips were washed with PBS (containing $\mathrm{Ca}^{2+}$ and $\mathrm{Mg}^{2+}$ ions; Gibco) and then digested with collagenase XI S (Sigma) overnight. Samples were then washed with PBS and placed in a $150 \mathrm{ml}$ cell culture flask (Costar-Nunc) containing standard culture medium based on Dulbecco's Modified Eagle Medium DMEM medium (Gibco) supplemented with foetal bovine serum (FBS) (10\%) (Gibco), l-glutamine (1\%) (Gibco), antibiotic-antimycotic solution $(1 \%)$ (Gibco) and L-ascorbic acid 2-phosphate $(120 \mathrm{mM})$ (Sigma). Cells were cultured in a $\mathrm{CO}_{2}$ incubator (at $37^{\circ} \mathrm{C}$ in $5 \% \mathrm{CO}_{2}$, humidified atmosphere). The medium was changed every seven days. Cell migration from the bone chips occurred within 2-4 weeks. After reaching a confluence, the HBDCs were used in experiments.

The authors obtained the approval from the Bioethics Committee of the Medical University of Warsaw for the experimental use of human cells from tissues harvested during surgery.

\subsection{Cell culture on dense ceramic disks}

The sterile dense disks due to their dimensions $(6 \mathrm{~mm}$ in diameter) were tightly fixed into the wells of 96-well culture dishes. The cells were seeded on the disks surfaces in the following concentrations: 15,000 cells per ceramic disk for quantitative assays, and 5000 cells per ceramic disk for morphology assessment and image analysis. HBDCs cultured on the tissue culture polystyrene well (TCPS) were used as a control.

After three days, a standard culture medium (described above) was changed to the osteogenic medium, i.e. standard medium supplemented with $10 \mathrm{nM}$ dexamethasone (Sigma) and $14 \mathrm{mM} \beta$-glycerophosphate disodium salt (Sigma). The osteogenic medium was changed every two days.

The HBDCs culture lasted up to ten days at $37^{\circ} \mathrm{C}$ in a $5 \% \mathrm{CO}_{2}$ incubator.

\subsection{Dynamic and static cell culture on the porous ceramic scaffolds}

The HBDCs were seeded on the scaffolds in a commercially available Spinner Basket ${ }^{\circledR}$ bioreactor (dynamic culture conditions) and on the scaffolds placed in 24-well culture dish (static conditions). One million cells per scaffold was used.

For a dynamic culture, scaffolds were located in the basket in the upper part of the bioreactor. The cell suspension in $500 \mathrm{ml}$ of a standard culture medium was then added to the bioreactor. The basket was instantly placed in the incubator $\left(37^{\circ} \mathrm{C}\right.$ in $\left.5 \% \mathrm{CO}_{2}\right)$ on the magnetic stirrer (speed $\left.\approx 60 \mathrm{rpm}\right)$. Due to the inner construction of the bioreactor, which extorted the direction of the medium movement, the continuous medium flow through the scaffolds was applied. The standard culture medium was changed to the osteogenic medium (described above) on day seven. The culture was continued up to five weeks. The $20 \%$ of the medium was changed twice a week.

In parallel to dynamic culture, static culture of HBDCs was performed on the porous scaffolds located in 24-well culture disks. The medium (1.5 $\mathrm{ml}$ in each well) was changed at the same time points as in the bioreactor and the observation time was the same, i.e. five weeks. 


\subsection{Cell viability assay $(X T T)$}

The HBDCs viability was assessed in the culture on dense disks (in 96-well culture dishes) - on day 3 and 10, as well as on porous scaffolds (in 24-well culture dishes) - after 3 and 5 weeks. The cellsscaffold constructs incubated in dynamic conditions were taken out of the bioreactor after 3 or 5 weeks placed into 24-well dishes in order to perform the cell viability test.

Cell viability was assessed by the 2.3-bis(2methoxy-4-nitro-5-sulfophenyl)-5-[(phenyloamino) carboxyl]-2H-tetrazolium hydroxide (XTT) assay. The assay is based on the capacity of mitochondrial dehydrogenase enzymes in living cells to convert the yellow water-soluble substrate into a highly colored water-soluble product. The amount of colored product is proportional to the number of living cells and their metabolic activity.

The cultures were washed with PBS and then XTT (0.45 mM, Sigma) and phenazine methosulphate (7.5 $\mu \mathrm{M}$, Sigma) solution in DMEM were added in a volume of $0.17 \mathrm{ml}$ per well of the 96-well dish or $1.02 \mathrm{ml}$ per well of the 24-well dish.

After $4 \mathrm{~h}$ incubation in $37^{\circ} \mathrm{C}$, supernatants $(0.12 \mathrm{ml})$ were collected and their absorbance was read in a microplate ELISA reader at $450 \mathrm{~nm}$.

\subsection{Cell differentiation assay}

Cell differentiation was assessed with alkaline phosphatase (ALP) enzymatic activity which is considered a good marker of early stages of osteoblast differentiation. The assay was performed on day 10 in the HBDCs culture on the dense disks and after 5 weeks in cell culture on the porous scaffolds.

Alkaline phosphatase activity was quantified by ALP Assay Kit (Sigma). The cell lysates were prepared by adding $0.1 \mathrm{ml}$ of $10 \mathrm{mM}$ TrisHCl-0.1\% Triton X-100 into each well of the 96-well dishes or $1 \mathrm{ml}$ into a well of 24-well dish. The conversion of paranitrophenylphosphate to para-nitrophenol by ALP lasted $30 \mathrm{~min}$ in room temperature and the absorbance was measured in a microplate ELISA reader at $405 \mathrm{~nm}$.

\subsection{Total protein content on the porous ceramics}

The total protein content was evaluated after 5 week cell culture on the porous scaffolds with Pierce BCA Kit according to manufacturer's instructions.

\subsection{Cell morphology and cells distribution within the scaffolds - Image analysis}

The cells were fixed with glutaraldehyde and stained with a DNA-specific Hoechst33342 dye (Sigma) on the day 3 - for morphology assessment on the dense ceramic disks and after 5 weeks of dynamic and static culture on the 3D porous scaffolds - for visualizing cell distribution. Cells morphology was visualized on the dense samples due to the aldehyde-related fluorescence (excitation 510-560 nm; emission: $575 \mathrm{~nm}$ ) and nuclei distribution either on the surface of the ceramic disks or on the surface of the scaffolds was detected at UV light (excitation: $355 \mathrm{~nm}$; emission: $460 \mathrm{~nm}$ ) in a fluorescent microscope (NIKON ECLIPSE TE 2000-U) with Digital Sight DS-U1 camera.

On the dense samples an image analysis has been performed as follows: corresponding pictures of the cell nuclei (Hoechst fluorescent dye) and cytoplasm (glutaraldehyde-induced fluorescence) on the dense disks and control wells were taken and then assessed quantitatively by a MicroMeter software designed at the Faculty of Materials Science and Engineering, University of Technology in Warsaw. The analysis was performed before cells reached confluence in order to let them spread freely. 
The pictures were originally saved in 256 shades of grayscale. Shadow correction was performed to eliminate the non-uniform lighting of the photographs. Gaussian filter $(3 \times 3$ matrix $)$ was applied in order to remove digital imaging artifacts. The images were subjected to binarization to show essential elements of structure like cells. To recognize the cells we assigned each pixel with white color. The binarization threshold was determined with manual method based on grayscale histogram distribution of gray images.

The following parameters were measured: the number of cells per unit area, mean cell area, equivalent diameter of the cell projected on the analyzed surface (d2), cell elongation (shape factor $\alpha$ ) and variation of curvature (shape factor $\beta$ ).

\subsection{Statistical analysis}

To verify the significance of observed differences in the cell functions, number and morphology between the examined ceramics and time points, one-way ANOVA, with post hoc Tukey's Multiple Comparison Test were used. The differences were considered statistically significant at $p<0.05$. The analysis was performed using GraphPad Prism software.

\section{Results and discussion}

\subsection{Calcium phosphates dense disks and porous scaffolds characteristics}

For the study three CaPs materials, i.e. $\alpha \mathrm{TCP}, \mathrm{CHA}$ and $\mathrm{BCP}$ were generated (see Table 1 for the detailed characteristics). Total porosity of the porous scaffolds ranged from $\sim 66$ to $\sim 83 \%$ while for the dense forms the value was $\sim 1-2 \%$. The microstructure of the sintered bioceramics is presented in Fig. 1. The obtained porous scaffolds contained approximately spherical macropores, of about $650 \mu \mathrm{m}$ in diameter. Although the scaffolds were prepared according to the same protocol, surface morphology differed among the materials as can be seen on the pictures (Fig. 1). Particularly, micropores below $1 \mu \mathrm{m}$ in diameter could be noticed on the surface of dense $\alpha \mathrm{TCP}$. The cell-contact surface was similar but not identical comparing the flat samples and the 3D scaffolds for each particular material.

\subsection{HBDCs cultured on the dense ceramic disks of BCP, CHA and $\alpha T C P$}

\subsubsection{Cell viability}

Viability of HBDCs after 3 days of culture on the surface of dense BCP disks was comparable to the TCPS control, as determined in the XTT assay (Fig. 2(a)). Although viability of cells cultured on CHA and on $\alpha \mathrm{TCP}$ was significantly lower, still it reached the $78 \%$ and $81 \%$ of the control, respectively. After 10 days, cell viability on the ceramic surfaces was comparable for all the ceramic types and reached about $75 \%$ of the control (Fig. 2(b)). The results of XTT assay reflect the activity of the mitochondrial enzyme. Therefore, if cells metabolism is not affected by the experimental treatment, the XTT assay provides the information about the size of the living, i.e. metabolic active cells in the population. Since the starting cell number was equal in all groups and the cells were not exposed to any toxic substances, XTT assay results can be indirectly interpreted as a marker of cell proliferation. Under the particular conditions of this experiment, cells reached confluence between the day 3 and 10. Therefore, cell viability measured on day 10 may be influenced not only by a direct cell-material contact but also by cell-cell relations. For that reason, the results on the day 3 (Fig. 2(a)) are more demonstrative for 

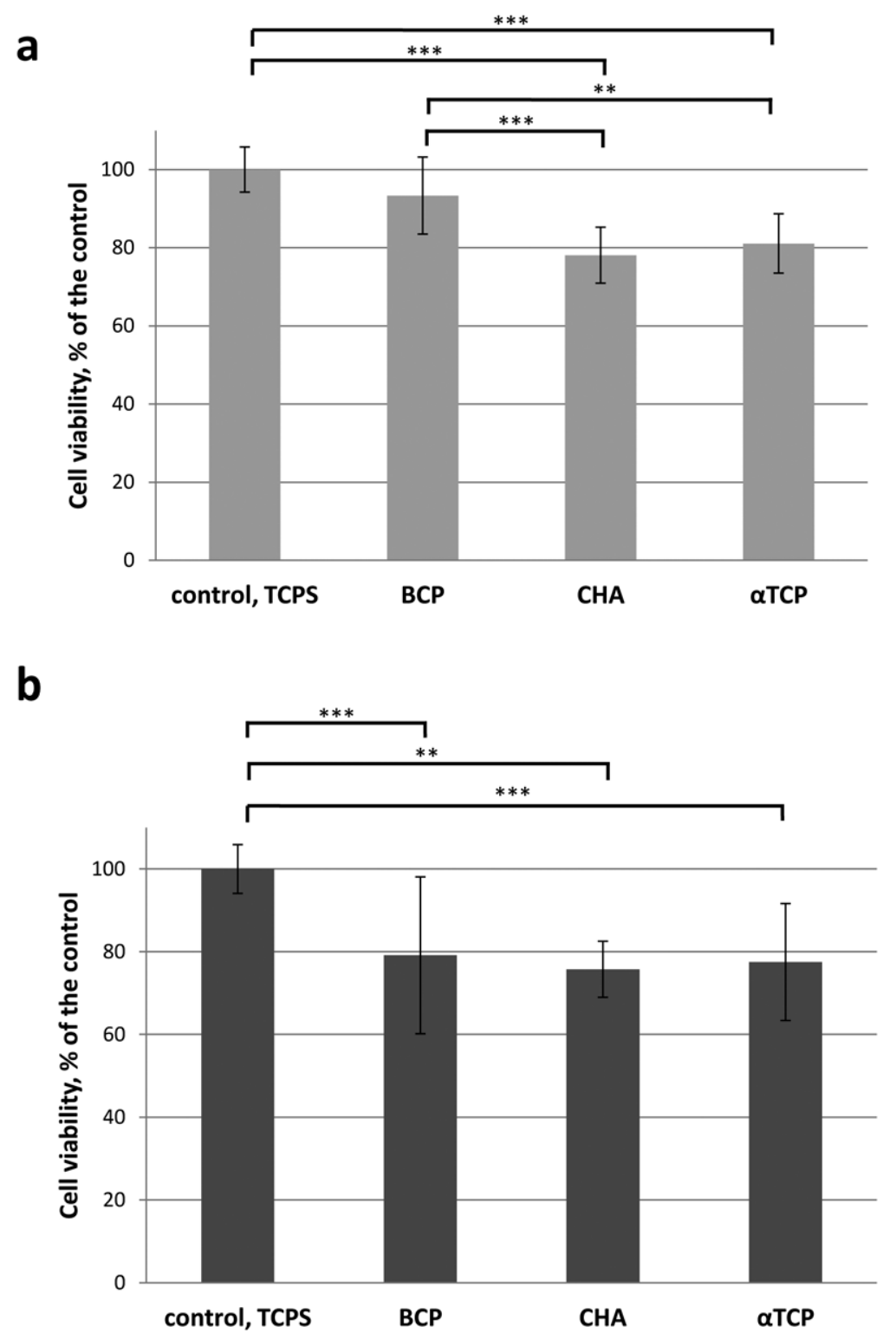

Fig. 2. Cell viability (XTT assay) assessed in HBDC culture on the dense BCP, CHA and $\alpha$ TCP ceramics disks. The results are presented as a $\%$ of the control, i.e. the HBDCs cultured on the tissue culture polystyrene: (a) after 3 days of culture, (b) after 10 days of culture $\left({ }^{* *} p<0.01,{ }^{* * *} p<0.001\right)$.

the material-dependent cell viability. In this way, BCP should be indicated as the most suitable matrix for cell proliferation of the tested materials. Nevertheless, good tolerance of HBDCs of all investigated ceramics has been confirmed.

\subsubsection{Alkaline phosphatase activity}

The alkaline phosphatase activity has been normalized to the values obtained in the XTT assay indicating the size of the living cells population. Alkaline phosphatase activity after 10 day cell culture on the dense ceramic samples was found to be the highest for BCP (6.2 Sigma Units, comparing to 


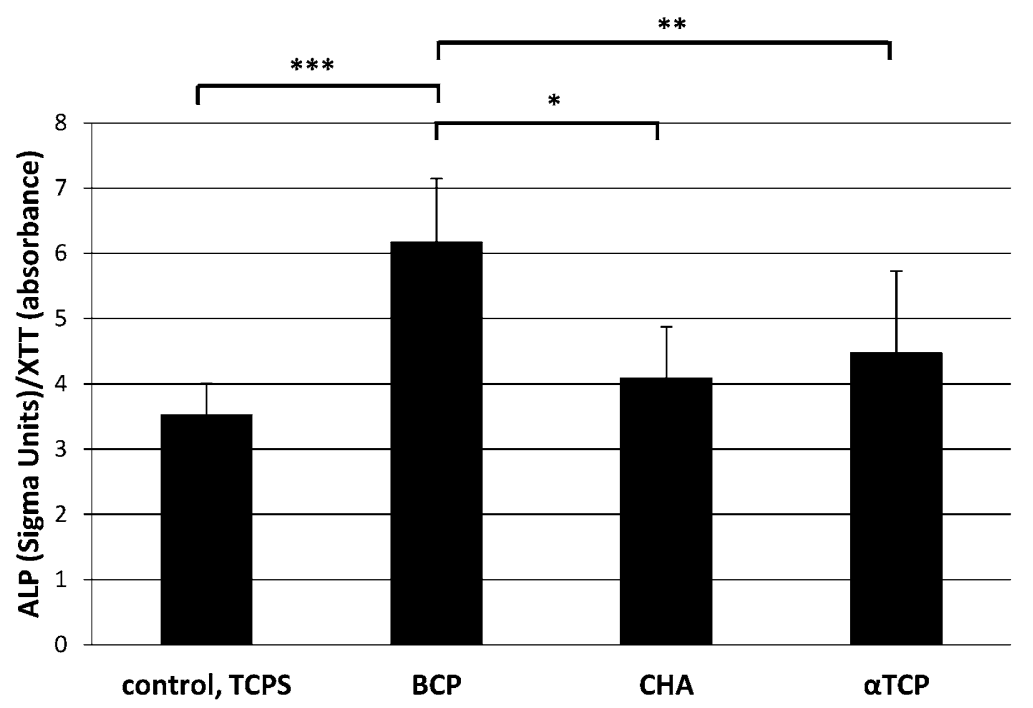

Fig. 3. Alkaline phosphatase activity assessed in HBDC culture on solid ceramic disks (BCP, CHA and $\alpha$ TCP) after 10 days of culture. HBDC cultured on the tissue culture polystyrene served as a control. The results are normalized to the values of absorbance read in the XTT assay for the same cell populations $\left({ }^{*} p<0.005,{ }^{* *} p<0.01,{ }^{* * *} p<0.001\right)$.

3.5 Sigma Units in the control - data normalized to the absorbance from XTT assay). Values obtained on the CHA (4.1 Sigma Units) and $\alpha$ TCP (4.5 Sigma Units) were not significantly higher than in the control, but they were significantly lower comparing to BCP (Fig. 3). Although ALP is not a specific marker of the osteoblastic phenotype, it is commonly accepted as an early marker of the osteogenic cell differentiation and it accompanies osteogenic activity of bone-forming cells. The obtained results add a further feature in support of BCP rather than the other investigated ceramics.

\subsubsection{Cell morphology and image analysis}

The HBDCs observed in a fluorescent microscope were homogeneously distributed on the surface of all the ceramic disks as well as in the TCPS control (Fig. 4(a-d)). Image analysis of the cells nuclei and cell shape revealed that the number of cells per sample (either the ceramic disk or the bottom of the TCPS well) was significantly higher on the BCP and $\alpha \mathrm{TCP}$ ceramics than on the CHA or the control (Fig. 4(e)). On the other hand HBDCs were the least spread on the BCPs - the average cell area as well as the equivalent diameter of the cell projected on the analyzed surface (d2) was significantly lower on BCPs than on the any other surface (Fig. 4(f), (g)).

Elongation of the HDBC (shape factor $\alpha$ ) (Fig. 4(h)) was comparable to the control on the CHA disks, while the cells were significantly more elongated on the $\alpha$ TCP disk and more rounded (significantly lower $\alpha$-factor) on the BCP. Variation of the cell curvature (shape factor $\beta$ ) (Fig. 4(i)) was significantly lower on the $\mathrm{BCP}$ and significantly higher on $\mathrm{CHA}$ and $\alpha \mathrm{TCP}$ comparing to the control.

Thus, both the size and the shape of HBDCs growing on BCP differed considerably as compared to the CHA and $\alpha \mathrm{TCP}$, which is an unexpected result given that the chemical structure of all investigated materials is similar. However, there is a common agreement that cell shape after spreading depends on many factors characterizing the cell-supporting surface [24]. There are also many data showing that cell spreading is correlated with cell wellness and its function [25]. For example, Saos-2 cells which grow more round on hydroxyapatite than on titanium were reported to exhibit more advanced differentia- 

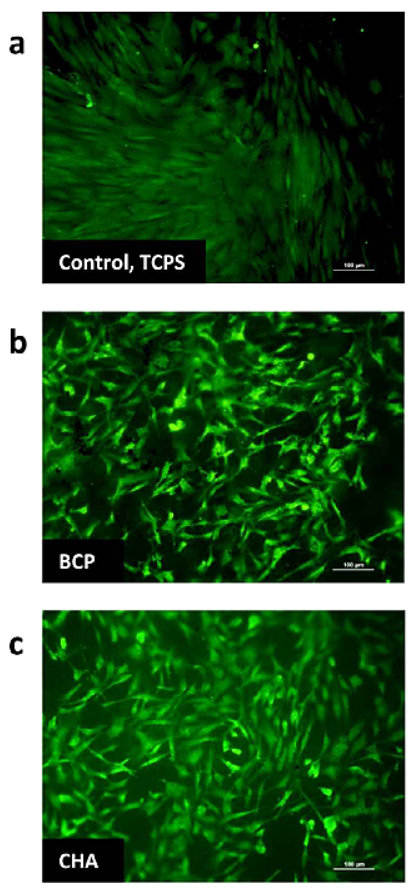

d

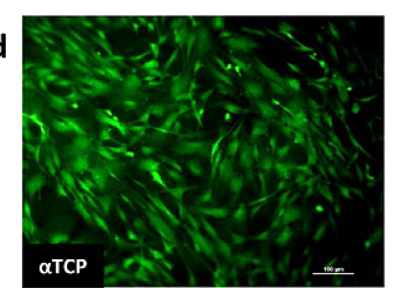

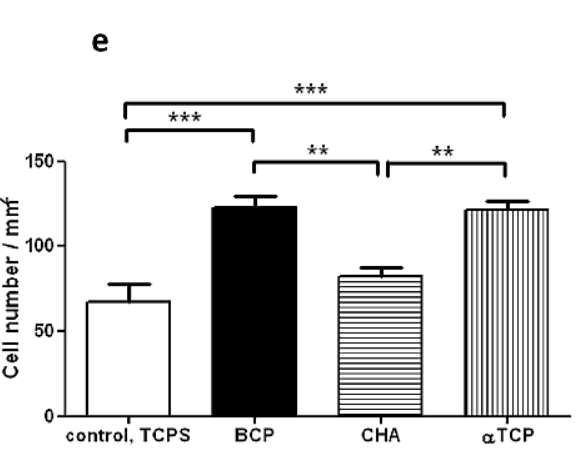

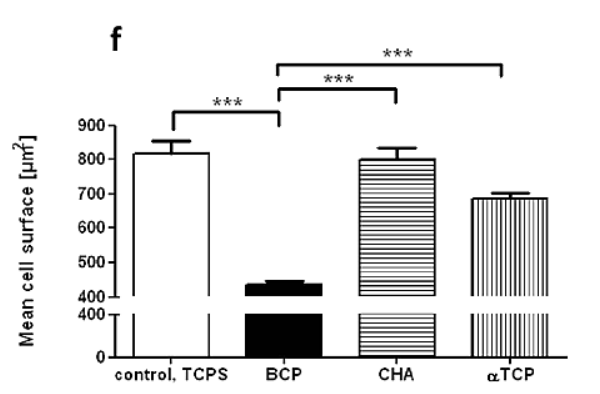

g

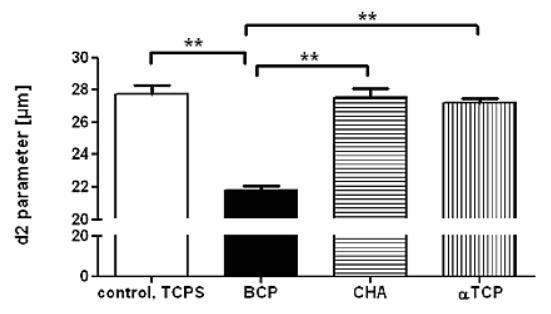

h

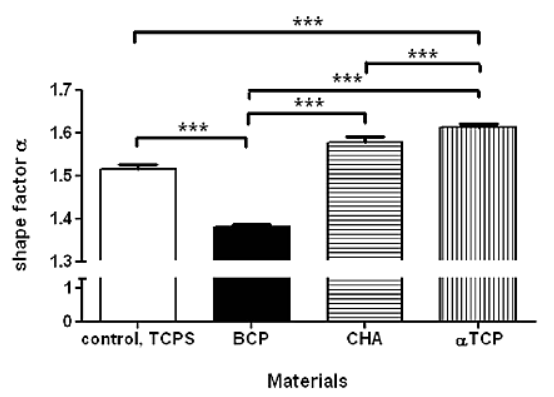

i

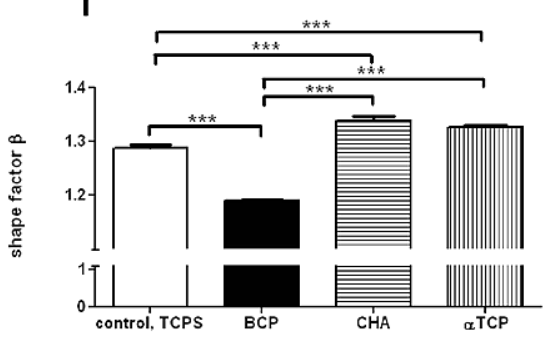

Fig. 4. Morphology of HBDCs cultured for 3 days on the dense samples of BCP (b), CHA (c), $\alpha$ TCP (d) and on tissue culture polystyrene (TCPS) (a) (glutaraldehyde-induced fluorescence). Results of the image analysis, i.e., cell number (e), mean cell surface (f), equivalent diameter of the cell projected on the analyzed surface $-\mathrm{d} 2$ parameter $(\mathrm{g})$, cell elongation - shape factor $\alpha(\mathrm{h})$, variation of curvature - shape factor $\beta$ (i). (Colors are visible in the online version of the article; http://dx.doi.org/10.3233/BME-140965.)

tion [26]. Also in our study, more round HBDCs on BCP dense disk exhibited more alkaline phosphatase activity than the cells on CHA, $\alpha \mathrm{TCP}$ or culture dish.

However, although many particular results have been published on the potential relation between cell shape and cell fate, they are ambiguous and there is still no systematic knowledge regarding mechanisms which are responsible for those phenomena. Understanding the nature of the observed phenomena require further studies.

\subsection{HBDCs cultured on the porous ceramic scaffolds of BCP, CHA and $\alpha T C P$ in static and dynamic conditions}

\subsubsection{Cell viability}

The results of XTT assay, performed after three and five weeks of culture on the porous scaffolds of three types are shown in Fig. 5. In general, independent on the time or conditions, cell viability was clearly the highest on the BCP scaffolds - values obtained in XTT assay were more than twice higher 


\section{a}

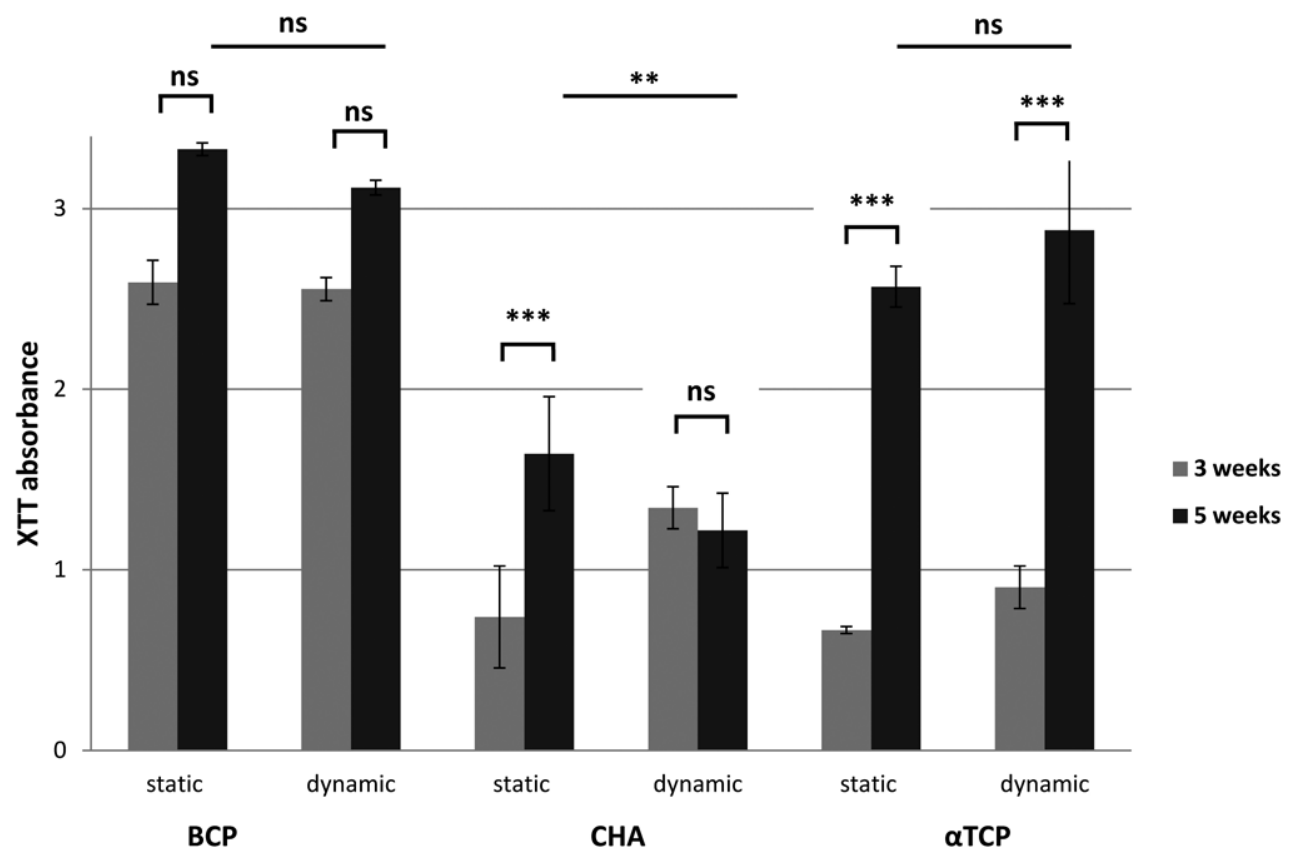

b

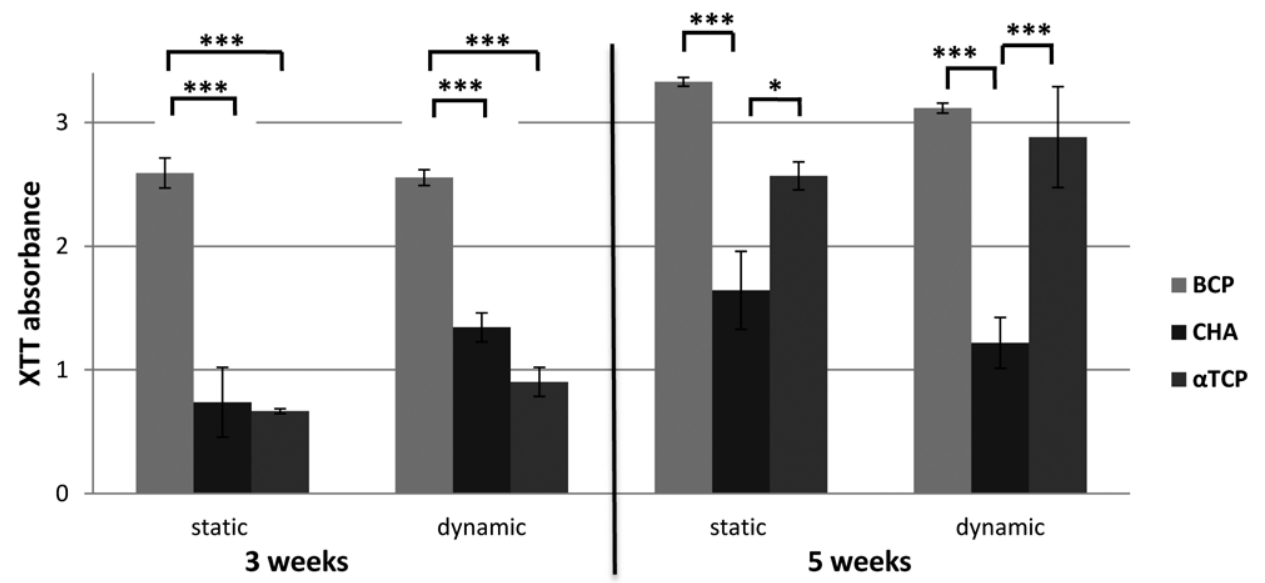

Fig. 5. The viability (XTT assay) of HBDCs cultured on the porous ceramic scaffolds (BCP, CHA and $\alpha$ TCP) under dynamic and static conditions after 3 and 5 weeks. To show all statistical relations between the analyzed groups the same results are shown for (a) the type of the material and (b) the culture conditions (static or dynamic) $\left({ }^{*} p<0.005,{ }^{* *} p<0.01\right.$, $\left.{ }^{* * *} p<0.001\right)$.

comparing to the other materials after three weeks in culture. The population of living i.e. metabolic active cells was rising between the third and the fifth week in culture, both under static and dynamic conditions for almost all materials. The exception were CHA scaffolds where the above was true only under static conditions. However, the rate of this growth was different. On BCP differences in the size of living cell population after three and five weeks were not significant independent on the culture con- 
ditions, while they were significant and particularly high (about 3-fold) on $\alpha \mathrm{TCP}$, both in static and dynamic culture. In the latter one it resulted in the final (measured after 5 weeks) cell viability comparable to those found on BCP (no statistically significant differences). It may be a consequence of more advanced differentiation process on BCP comparing to $\alpha \mathrm{TCP}$ (discussed below) which may slow down cell proliferation. Anyway, cell population after 5 weeks on BCP is at least equally high comparing to $\alpha \mathrm{TCP}$ and about twice higher than on CHA. Interestingly, in all cases, the size of living cell population was not affected by applying the dynamic culture conditions.

Similarly to the cell viability evaluated in a culture on the flat samples (Fig. 2) BCP turned out to be the most favorable support for HBDCs also in the form of 3D scaffolds.

\subsubsection{Cell differentiation}

Alkaline phosphatase activity (ALP) measured in cell lysates after five weeks of culture within ceramic scaffolds under either dynamic or static conditions is shown in Fig. 6. It has been normalized to the XTT assay results representing the number of living cells.

ALP activity was found to be the highest in cells growing on the BCP scaffolds independently on the culture conditions. Values obtained on BCP were 3-fold higher comparing to $\alpha \mathrm{TCP}$ (8.74 Sigma Units vs 2.31 in a dynamic culture and 3.88 comparing to 1.17 on $\alpha \mathrm{TCP}$ in static conditions - all values normalized to the size of a living cells population measured in XTT assay). Differences between the values obtained for BCP and CHA were not significant (Fig. 6(a)). In all cases ALP activity was higher when the culture was performed in the bioreactor. For both BCP and CHA differences between the values measured in the static culture and the dynamic one were statistically significant (3.88 Sigma units vs 8.74 and 2.79 vs 7.44 respectively).

On the basis of these results it can be concluded that the osteogenic capacity of HBDCs in 3D culture on Ca-P scaffolds - as expressed by the ALP activity - is significantly promoted by applying a permanent medium flow through the scaffolds. Such phenomenon was reported by others also when using another systems of dynamic culture conditions of bone-marrow-derived-cells on the porous ceramic scaffolds $[9,27,28]$.

The results showing the highest ALP activity on the 3D BCP scaffolds as compared to $\alpha$ TCP and $\mathrm{CHA}$ is in a good agreement with the results obtained in a 2D culture on the investigated ceramics. This gives yet another reason to recommend $\mathrm{BCP}$ as a support for osteogenic cells transplantation.

\subsubsection{Total protein content}

The total protein content in five weeks cultures of HBCDs on the porous ceramic scaffolds is presented in Fig. 7.

Protein content is comparable between all the ceramic types in static culture. However, there is a significant difference in protein content on each scaffold between static and dynamic conditions, which is particularly high on the BCP scaffolds.

Since the number of cells in tested population did not depend on culture conditions, the significantly higher total protein content in dynamic culture comes probably from the extracellular proteins. Thus, it is proposed that a dynamic culture conditions applied in our experiment promote the production of extracellular matrix by HBDCs in 3D Ca-Ps scaffold. Again, results for BCP are the most encouraging.

\subsubsection{Cell distribution within scaffolds}

The HBDCs were homogeneously distributed within all the scaffolds when the cell seeding and culture was performed in a bioreactor. Under the static conditions after five weeks culture more cells grew on the upper surface of the scaffolds than on the bottom side, independently on the material (not shown). 
a
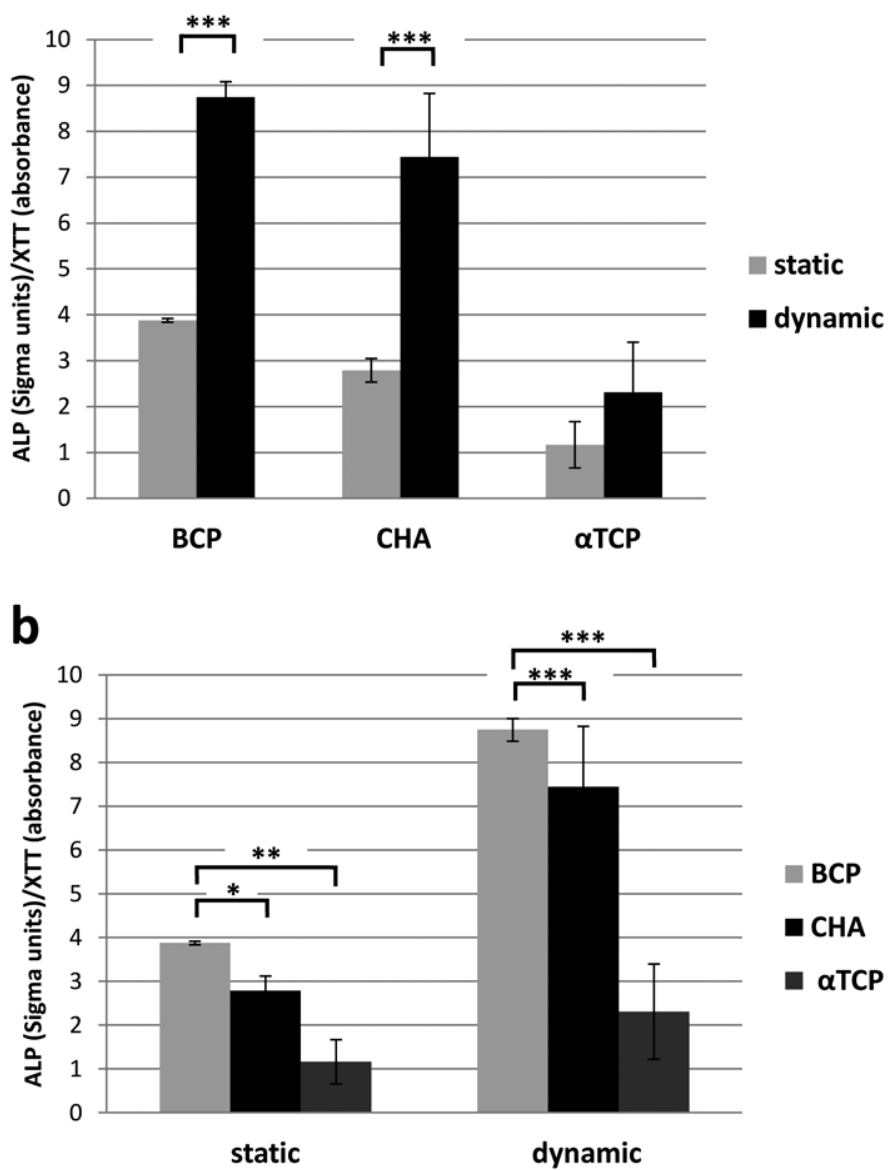

Fig. 6. Alkaline phosphatase activity assessed in HBCDs cultures on the porous ceramic scaffolds (BCP, CHA and $\alpha$ TCP) under dynamic and static conditions after 5 weeks. The results are normalized to the values of absorbance read in the XTT assay for the same cell populations. The same results are shown for the type of the material (a) or the culture conditions (static or dynamic) (b). This is in order to show all statistical relations between the analyzed groups $\left({ }^{*} p<0.005,{ }^{* *} p<0.01\right.$, $\left.{ }^{* * *} p<0.001\right)$.

An improvement of the homogeneity in cells distribution within the scaffolds is the most often reported advantage of the dynamic over the static culture conditions [6,22]. A regular cell localization obtained by using a Spinner Basket ${ }^{\circledR}$ bioreactor has been already reported by our group when smaller i.e., $6 \mathrm{~mm}$ in diameter and $4 \mathrm{~mm}$ in height polyurethane scaffolds were used [29]. Here, we confirmed that the applied dynamic culture conditions are efficient also for larger ceramic scaffolds (disks of $12 \mathrm{~mm}$ in diameter and $4 \mathrm{~mm}$ in height).

\section{Conclusions}

From among the three investigated Ca-Ps ceramics potentially desirable as scaffolds for BTEPs, i.e., BCP, $\alpha$ TCP and CHA, BCP was found to be optimal for HBDCs both on the flat and the 3D scaffolds and in static and dynamic culture conditions. In particular, number of living cells in short and prolonged 
a
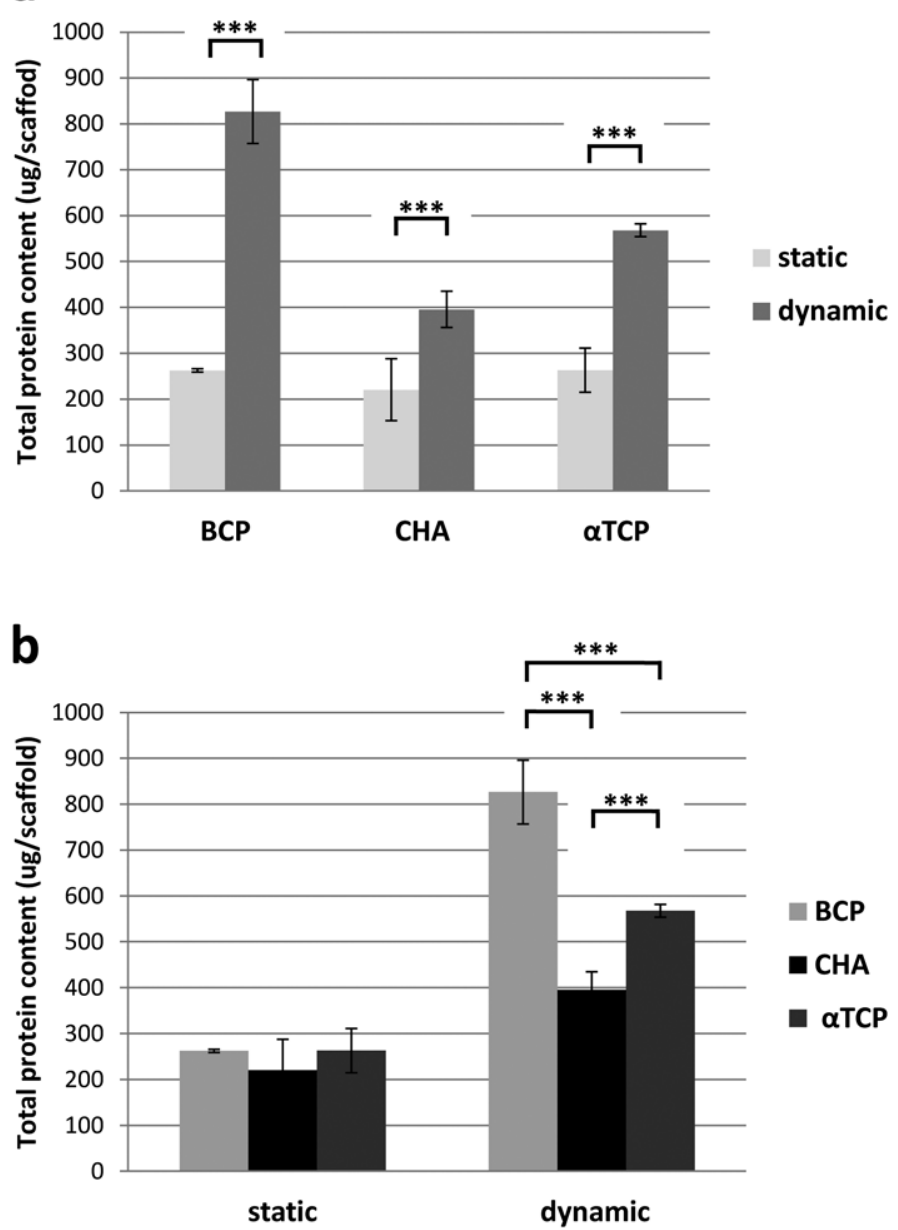

Fig. 7. Total protein content ( $\mu \mathrm{g} / \mathrm{scaffold}$ ) in HBCDs cultures on the porous ceramic scaffolds (BCP, $\mathrm{CHA}$ and $\alpha \mathrm{TCP})$ under dynamic and static conditions after 5 weeks of culture. The same results are shown grouped regarding either the type of the material (a) or the culture conditions (static or dynamic) (b). $\left({ }^{* * *} p<0.001\right)$.

observation, their osteogenic capacity assessed by the ALP activity, and extracellular matrix production in a 3D scaffold, were significantly higher on BCP in comparison with the other investigated Ca-Ps. In addition, the shape of HBDCs growing on flat BCP differed as compared to the other ceramics. This observation does not seem accidental, although we are not able to indicate the nature of the phenomenon. It should be underlined that all the evaluated ceramics were prepared using the same technology in one laboratory which strengthen the comparative value of the presented results. Therefore the obtained data could validate the recommendation of BCP as the suitable matrix for osteogenic cells expansion and differentiation prior to implantation in a tissue engineered system.

Additionally, improved cell distribution within the 3D scaffolds, enhanced production of the extracellular matrix as well as more advanced osteogenic capacity of HBDCs - as can be judged by ALP activity - were confirmed for all investigated materials when a Spinner Basket ${ }^{\circledR}$ bioreactor was applied. Even though the size of cell population did not augment under dynamic conditions in comparison to 
the static culture, these findings give a good reason to utilize the dynamic system for cell culture in 3D scaffolds intended for use in tissue engineering.

\section{Acknowledgements}

This work was supported by grants 3T08A01829 and NN507469937 from Polish Ministry of Education and Science.

\section{References}

[1] J.O. Eniwumide, H. Yuan, S.H. Cartmell, G.J. Meijer and J.D. de Bruijn, Ectopic bone formation in bone marrow stem cell seeded calcium phosphate scaffolds as compared to autograft and (cell seeded) allograft, Eur. Cell Mater. 14 (2007), $30-38$.

[2] R.Z. LeGeros, Calcium phosphate-based osteoinductive materials, Chem. Rev. 108 (2008), 4742-4753.

[3] M. Bohner, L. Galea and N. Doebelin, Calcium phosphate bone graft substitutes: Failures and hopes, J. Eur. Ceram. Soc. 32 (2012), 2663-2671.

[4] Bone graft substitutes materials, available at: http://emedicine.medscape.com/article/1230616-overview [cited 19 June 2013].

[5] M. Bohner, Design of ceramic-based cements and putties for bone graft substitution, Eur. Cell Mater. 20 (2010), 1-12.

[6] M.P. Ginebra, M. Espanol, E.B. Montufar, R.A. Perez and G. Mestres, New processing approaches in calcium phosphate cements and their applications in regenerative medicine, Acta Biomater. 6 (2010), 2863-2873.

[7] R. Krüger and J. Groll, Fiber reinforced calcium phosphate cements - On the way to degradable load bearing bone substitutes?, Biomaterials 33 (2012), 5887-5900.

[8] S. Sanchez-Salcedo, I. Izquierdo-Barba, D. Arcos and M. Vallet-Regi, In vitro evaluation of potential calcium phosphate scaffolds for tissue engineering, Tissue Eng. 12 (2006), 279-290.

[9] T. Uemura, J. Dong, Y. Wang, H. Kojima, T. Saito, D. Iejima et al., Transplantation of cultured bone cells using combinations of scaffolds and culture techniques, Biomaterials 24 (2003), 2277-2286.

[10] A.M.C. Barradas, H. Yuan, C.A. van Blitterswijk and P. Habibovic, Osteoinductive biomaterials current knowledge of properties, experimental models and biological mechanisms, Eur. Cell Mater. 21 (2011), 407-429.

[11] E. Verron, J.M. Bouler and J. Guicheux, Controlling the biological function of calcium phosphate bone substitutes with drugs, Acta Biomater. 8 (2012), 3541-3551.

[12] H. Liu, H. Yazici, C. Ergun, T.J. Webster and H. Bermek, An in vitro evaluation of the $\mathrm{Ca} / \mathrm{P}$ ratio for the cytocompatibility of nano-to-micron particulate calcium phosphates for bone regeneration, Acta Biomater. 4 (2008), 1472-1479.

[13] H. Yuan, C.A. van Blitterswijk, K. de Groot and J.D. de Bruijn, Cross-species comparison of ectopic bone formation in biphasic calcium phosphate (BCP) and hydroxyapatite (HA) scaffolds, Tissue Eng. 12 (2006), 1607-1615.

[14] A. Ehara, K. Ogata, S. Imazato, S. Ebisu, T. Nakano and Y. Umakoshi, Effects of alpha-TCP and TetCP on MC3T3-E1 proliferation, differentiation and mineralization, Biomaterials 24 (2003), 831-836.

[15] M. Yamada, M. Shiota, Y. Yamashita and S. Kasugai, Histological and histomorphometrical comparative study of the degradation and osteoconductive characteristics of alpha- and beta-tricalcium phosphate in block grafts, J. Biomed. Mater. Res. B Appl. Biomater. 82 (2007), 139-148.

[16] P. Habibovic, M.V. Juhl, S. Clyens, R. Martinetti, L. Dolcini, N. Theilgaard et al., Comparison of two carbonated apatite ceramics in vivo, Acta Biomater. 6 (2010), 2219-2226.

[17] E. Landi, G. Celotti, G. Logroscino and A. Tampieri, Carbonated hydroxyapatite as bone substitute, J. Eur. Ceram. Soc. 23 (2003), 2931-2937.

[18] P. Habibovic, M.C. Kruyt, M.V. Juhl, S. Clyens, R. Martinetti, R. Dolcini et al., Comparative in vivo study of six hydroxyapatite-based bone graft substitutes, J. Orthop. Res. 26 (2008), 1363-1370.

[19] R.Z. LeGeros, S. Lin, R. Rohanizadeh, D. Mijares and J.P. LeGeros, Biphasic calcium phosphate bioceramics: preparation, properties and applications, J. Mater. Sci. Mater. Med. 14 (2003), 201-209.

[20] K.K. Mathur, S.A. Tatum and R.M. Kellman, Carbonated apatite and hydroxyapatite in craniofacial reconstruction, Arch. Facial Plast. Surg. 5 (2003), 379-383.

[21] C. Schopper, F. Ziya-Ghazvini, W. Goriwoda, D. Moser, F. Wanschitz, E. Spassova et al., HA/TCP compounding of a porous CaP biomaterial improves bone formation and scaffold degradation - a long-term histological study, J. Biomed. Mater. Res. B Appl. Biomater. 74 (2005), 458-467. 
[22] A.M. Ng, K.K. Tan, M.Y. Phang, O. Aziyati, G.H. Tan, M.R. Isa et al., Differential osteogenic activity of osteoprogenitor cells on HA and TCP/HA scaffold of tissue engineered bone, J. Biomed. Mater. Res. A $\mathbf{8 5}$ (2008), 301-312.

[23] J. Gallagher, R. Gundle and J.N. Beresford, Isolation and culture of bone-forming cells (osteoblasts) from human bone, in: Methods in Molecular Medicine: Human Cell Culture Protocols, G.E. Jones, ed., Humana Press, Totowa, NJ, 1996.

[24] B.D. Boyan, T.W. Hummert, D.D. Dean and Z. Schwartz, Role of material surfaces in regulating bone and cartilage cell response, Biomaterials 17 (1996), 137-146.

[25] A.K. Born, M. Rottmar, S. Lischer, M. Pleskova, A. Bruinink and K. Maniura-Weber, Correlating cell architecture with osteogenesis: first steps towards live single cell monitoring, Eur. Cell Mater. 18 (2009), 49-60.

[26] A. Okumura, M. Goto, T. Goto, M. Yoshinari, S. Masuko, T. Katsuki et al., Substrate affects the initial attachment and subsequent behavior of human osteoblastic cells (Saos-2), Biomaterials 22 (2001), 2263-2271.

[27] Y. Wang, T. Uemura, J. Dong, H. Kojima, J. Tanaka and T. Tateishi, Application of perfusion culture system improves in vitro and in vivo osteogenesis of bone marrow-derived osteoblastic cells in porous ceramic materials, Tissue Eng. 9 (2003), 1205-1214.

[28] H.L. Holtorf, T.L. Sheffield, C.G. Ambrose, J.A. Jansen and A.G. Mikos, Flow perfusion culture of marrow stromal cells seeded on porous biphasic calcium phosphate ceramics, Ann. Biomed. Eng. 33 (2005), 1238-1248.

[29] P. Wozniak, M. Bil, J. Ryszkowska, P. Wychowanski, E. Wrobel, A. Ratajska et al., Candidate bone-tissue-engineered product based on human-bone-derived cells and polyurethane scaffold, Acta Biomater. 6 (2010), 2484-2493. 